\title{
Squamous cell carcinoma originated from chronic osteomyelitis sinus tract in tibia
}

\author{
Ahmet Aslan, MD (1) \\ Department of Orthopedics and Traumatology, Alanya Alaaddin Keykubat University, Faculty of Medicine, Antalya, Turkey
}

A 71-year-old female patient referred to the author's orthopedics outpatient clinic with the complaints of pain, purulent discharge and bad odor. Evaluation revealed a defect involving the skin, subcutaneous tissue and bone in the proximal right leg, the appearance of cauliflower and abnormal odor on the skin (Figure 1a). As far as it could be learned from the anamnesis of the patient, she had applied to the doctor about 60 years ago with complaints of pain, redness, swelling under the knee and, as far as understood, treatments such as analgesics, antibiotics, drainage and debridement were applied. The patient and their relatives stated that no results were obtained from the treatments, the sinus tract and defect in the leg increased over time, and pain and discharge increased from time to time. Afterwards, it was learned that the patient's treatment and follow-up were not performed regularly and that she did not go to the hospital for a long time. The patient was hospitalized with a preliminary diagnosis of chronic osteomyelitis as a result of her physical examination and hematological, radiological (Figure 1b, c) and microbiological examinations. The patient and her relatives were informed about her diagnosis and treatment options. Their consent was received. Following the necessary preparations, radical debridement was performed at the first stage

Received: March 28, 2020

Accepted: April 30, 2020

Published online: June 18, 2020

Correspondence: Ahmet Aslan, MD. Alanya Alaaddin Keykubat Üniversitesi, Eğitim ve Araştırma Hastanesi, Ortopedi ve

Travmatoloji Kliniği, 07425 Alanya, Antalya, Türkiye.

E-mail: draaslan@hotmail.com

Doi: $10.5606 /$ ehc. 2020.75084

Citation: Aslan A. Squamous cell carcinoma originated from chronic osteomyelitis sinus tract in tibia. Jt Dis Relat Surg 2020;31(2):405-407.
(Figure 2a, b), and the defect was filled with antibiotic bone cement (Figure 2c). As a result of microbiological and pathological examination of samples taken from intraoperative bone tissue, the diagnosis of
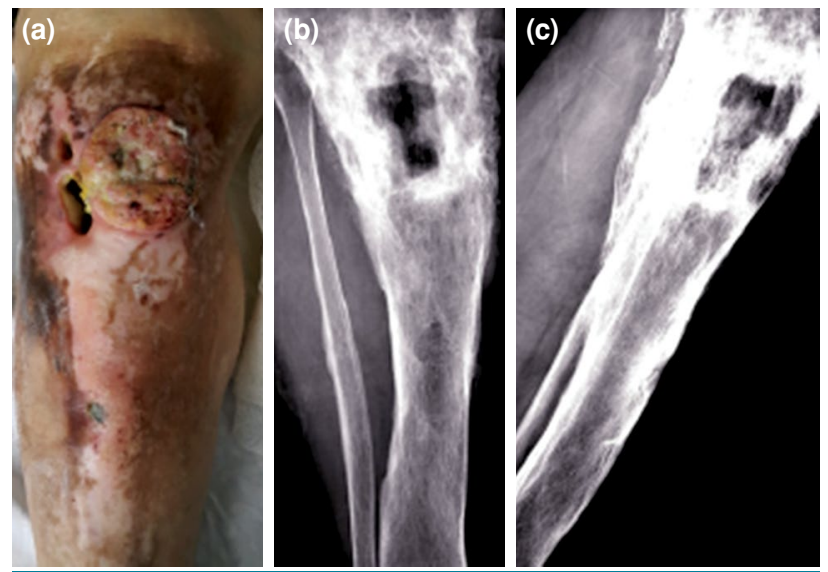

FIGURE 1. (a) Patient has a defect involving skin, subcutaneous and bone tissue in proximal right leg, appearance of cauliflower on skin. (b, c) Radiological images of right tibia at first application of patient.
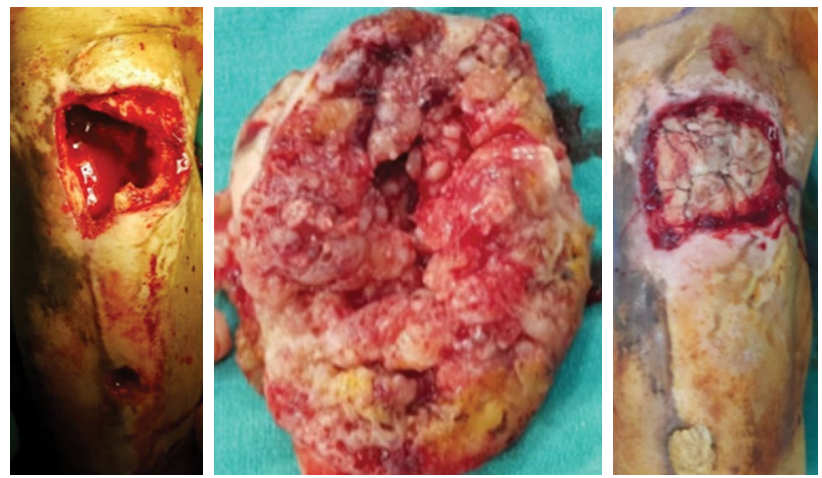

FIGURE 2. (a-c) Radical debridement was performed and defect of proximal tibia was filled with antibiotic bone cement at first stage surgery. 

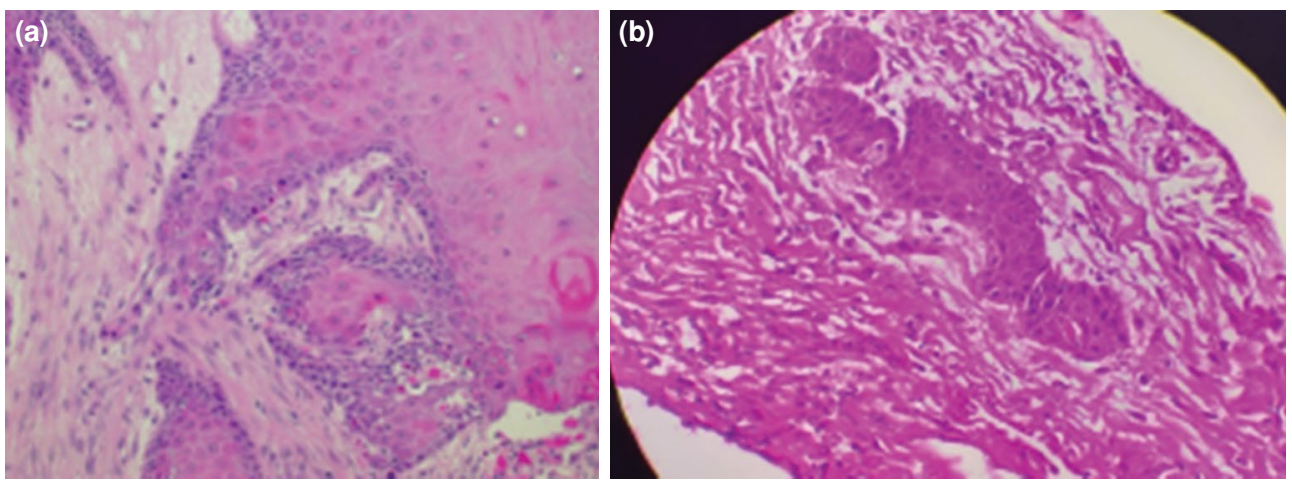

FIGURE 3. (a. b) Squamous cell carcinoma was diagnosed in pathological examination of soft tissue samples with atypical mitosis areas.

chronic osteomyelitis was confirmed. Squamous cell carcinoma was diagnosed in the pathological examination of soft tissue samples (Figure $3 a, b$ ) and bone invasion. The patient underwent scintigraphic screening for other focus and metastasis and was consulted by other relevant specialists. There were no palpable regional lymph nodes. Also, no other focus and/or metastases were detected. Upon the improvement of clinical and laboratory parameters in her follow-up, bone cement removal, debridement, gastrosoleus flap and grafting were performed at the second stage surgery (Figure 4a-c). During the three-year follow-up of the patient, osteomyelitis did not recur and no recurrence or metastasis related to squamous cell carcinoma was observed (Figures 5, 6). But in the fourth year, osteomyelitis recurred.

Treatment of chronic osteomyelitis of the long bones is challenging due to infection, bone defect and/or resection and other complications. Carcinomatous degeneration and transformation following chronic
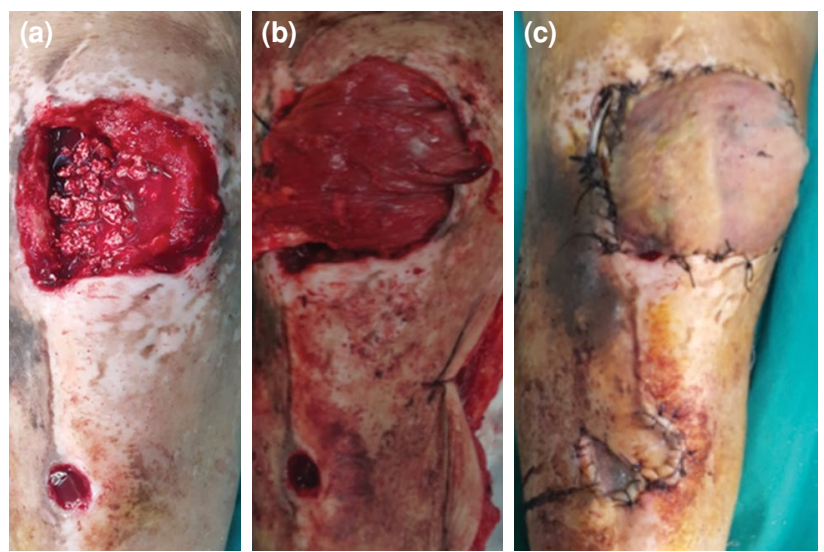

FIGURE 4. (a-c) Bone cement removal, debridement, gastrosoleus flap and grafting were performed at second stage surgery.

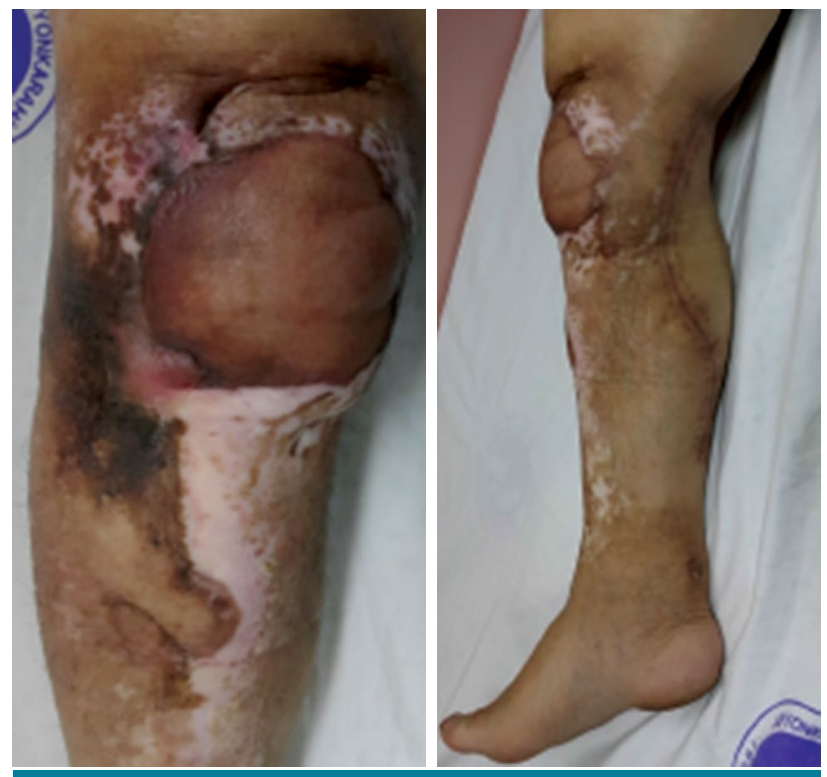

FIGURE 5. Clinical view of patient's leg at three-year follow-up.
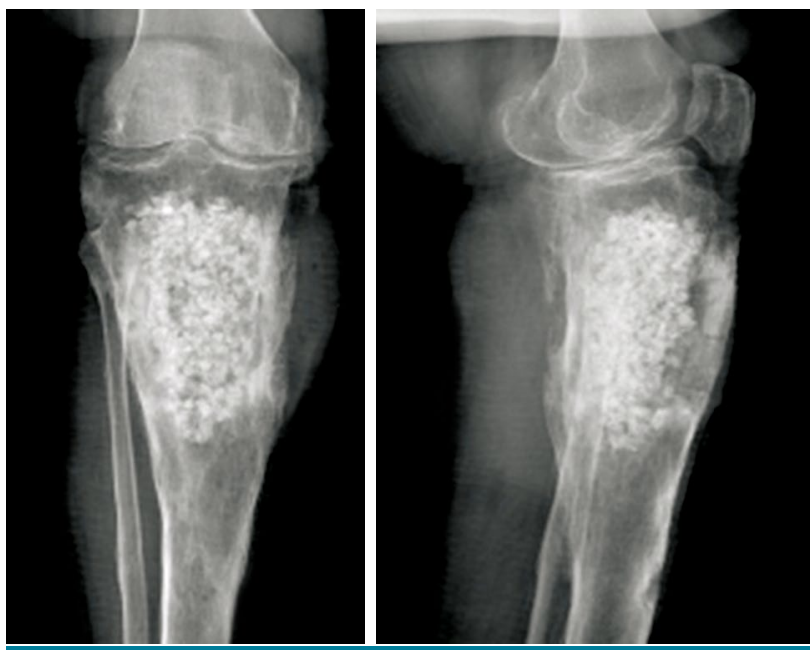

FIGURE 6. Radiological images of patient's leg at three-year follow-up. 
osteomyelitis is a rare and late complication. It is usually reported in the literature as case report or case series. In this article, a case report of squamous cell carcinoma that developed after years in chronic osteomyelitis sinus tract was presented with its novel treatment, follow-up and clinical pictures.

In many articles, squamous cell carcinoma on the background of chronic osteomyelitis has been reported in the $20-40^{\text {th }}$ year. It was detected in our case at the $60^{\text {th }}$ year. On the other hand, amputation is stated as the most effective treatment method in squamous cell carcinoma cases on the basis of chronic osteomyelitis. However, we tried to treat the patient with a different method due to the patient's refusal to amputation, no comorbid disease that may be a risk factor, absence of lymphadenopathy, no signs of metastasis and low grade of the tumor. Following radical debridement and excision with grafting, gastrosoleus flap and skin grafting, we observed that the patient was able to continue her daily life and was happy after four years of follow-up.

\section{Declaration of conflicting interests}

The author declared no conflicts of interest with respect to the authorship and/or publication of this article.

\section{Funding}

The author received no financial support for the research and/or authorship of this article. 